\title{
A Survey on Self-Medication in Ophthalmology in the Lebanese Population
}

\section{Alaa Bou Ghannam ${ }^{1}$, Ibrahim Hashim ${ }^{1}$, Ahmad Al Attar², Wajiha Jurdi Kheir $^{1}$, Julien Selim Torbey ${ }^{1}$, Hana A. Mansour ${ }^{1}$ and Joanna S. Saade ${ }^{1 *}$}

${ }^{1}$ Department of Ophthalmology, American University of Beirut Medical Center,

Beirut, Lebanon

${ }^{2}$ The American University of Beirut, Beirut, Lebanon

*Corresponding Author: Joanna S Saade, Cornea and Refractive Surgery,

Department of Ophthalmology, American University of Beirut Medical Center, Cairo

Street, Hamra, Beirut, Lebanon.
Received: March 29, 2021

Published: April 21, 2021

(C) All rights are reserved by Joanna S Saade., et al.

\section{Abstract}

Purpose: Over the counter eye drops are commonly used in the Lebanese population to manage eye redness and symptoms. We sought to investigate its prevalence in Lebanon by conducting a survey.

Methods: This is a cross-sectional prospective study done between November 2017 and March 2020. Volunteers above 18 years of age filled a questionnaire regarding participants' demographics as well as information about eye redness and related consultations and drop use.

Results: Of the 265 individuals studied, the majority were women (58.1\%). 111 individuals reported having red eyes in the last 5 years (41.9\%). Of these, $72.1 \%$ reported using drops, and $83.8 \%$ reported consulting someone for their symptoms (pharmacist, medical doctor, ophthalmologist, or others). Ophthalmologists were primarily consulted in 55.9\% of cases. Ophthalmologists and pharmacists were more likely to be consulted by individuals between 31 and 50, as opposed to non-healthcare-worker consultations who were more likely sought by individuals between 51 and 70 years $(p=0.038)$. Tearing $(p=0.002)$, foreign body sensation $(p>$ $0.001)$, and blurry vision ( $p=0.016)$ were correlated with consulting someone for eye redness. Tearing $(p=0.003)$ and foreign body sensation ( $p=0.002$ ) were correlated with drop use. Only $34.1 \%$ of drop users read instructions, and individuals with a college level of education were more likely to do so.

Conclusion: A large proportion of Lebanese patients will self-medicate with over-the-counter drops without consulting a medical doctor or reading the medication pamphlets. This can be potentially detrimental to patients' eyes, especially if they are unaware of the side effects.

Keywords: Self-Medication in the Middle East; Over the Counter Eye Drops Usage; Awareness to Medication Side Effects; Guidelines for Regulation of Dispensing of Medications

\section{Abbreviations}

NSAIDS: Non-Steroidal Anti-Inflammatory Drugs; OTC: Over the Counter; NSS: National Social Security

\section{Introduction}

Self-medication is recognized as the self-use of medicines to treat self-recognized symptoms or a self-diagnosed disease [1]. This includes the use of eye drops to treat eye symptoms. By not 
being aware of the side effects, appropriate dosage, length of treatment, and the right indications behind each eye drop, patients who self-medicate place themselves at some toxicological and pharmacological risk which can jeopardize their health or vision.

Many ophthalmological eye-drops and medications such as non-steroidal anti-inflammatory drugs (NSAIDs), steroids, vasoconstrictors or antibiotics are available over the counter (OTC) and do not require a prescription in Lebanon. However, their administration without adequate medical overview and assessment can carry detrimental side effects [2].

Steroids are well known to increase intra-ocular pressure and carry the risk of infections, stromal melt and cataract development $[3,4]$. With excessive use, NSAIDs have been shown to cause keratitis, with some reported cases of corneal melting [5]. Vasoconstrictors may create excessive rebound vasodilation and severe red eyes commonly known as papillary conjunctivitis [6]. Furthermore, unwarranted antibiotic treatment can lead to bacterial resistance and prevent adequate future treatment $[2,7]$.

\section{Aim of the Study}

Our aim in this study is to determine the incidence and causes of self-medication in Lebanon, as well as to assess the behavior of the general Lebanese population related to OTC ocular drops.

\section{Materials and Methods}

This prospective, observational, cross sectional study was conducted in the Outpatient Clinics at the Department of Ophthalmology at the American University of Beirut Medical Center, Lebanon, from November 2017 to March 2020 in adherence with the Declaration of Helsinki and after approval from the Institutional Review Board at our institution. Patients above 18 years of age who approved and agreed to participate in the study had to answer an anonymous survey of 29 questions. The main goal of the questionnaire was to detect the incidence of self-medication and other behaviors relating to ocular symptoms, as well as to assess individual knowledge about side effects and duration of OTC eye-drop use. The resulting data collected was analyzed with SPSS using the Chisquare and Fisher Exact test tools. For all our analysis, a p-value of less than 0.05 was considered significant.

\section{Results}

A total of 265 participants were enrolled in our study, nearly equally distributed among females: 154 (58.1\%) and males: 109 (41.1\%) (Table 1). One hundred and eleven individuals (41.9\%) reported having eye redness in the last five years, while 154 (58.1\%) reported they did not. Of those who did not have any red eye symptoms in the last 5 years, $67(43.5 \%)$ said they would consult a pharmacist if they ever had eye redness, and 36 (23.4\%) said they would consult a friend or relative for the same reason.

\begin{tabular}{|c|c|c|c|c|c|}
\hline & Gender & Age Group & Level of Education & Medical Coverage & Area of Residence \\
\hline \multirow{5}{*}{$\begin{array}{l}\text { Number of } \\
\text { Participants } \\
\text { and } \\
\text { Percentage } \\
(\%)\end{array}$} & $\begin{array}{l}\text { Male: } 109 \\
(41.1 \%)\end{array}$ & $\begin{array}{c}\text { Between } 18 \\
\text { and 30: } 66 \\
(24.9 \%)\end{array}$ & $\begin{array}{l}\text { Elementary School (a.k.a } \\
\text { Brevet): } 128 \text { (48.3\%) }\end{array}$ & Insurance: 48 (18.1\%) & $\begin{array}{l}\text { Beirut and its suburbs: } \\
\qquad 107(40.4 \%)\end{array}$ \\
\hline & $\begin{array}{c}\text { Female: } 154 \\
\quad(58.1 \%)\end{array}$ & $\begin{array}{c}\text { Between } 31 \\
\text { and 50: } 103 \\
(38.9 \%)\end{array}$ & $\begin{array}{c}\text { High School (a.k.a } \\
\text { Baccalaureate): } 42 \\
(15.8 \%)\end{array}$ & $\begin{array}{l}\text { National Social Security } \\
\text { (NSS): } 93(35.1 \%)\end{array}$ & $\begin{array}{l}\text { Outside Beirut: } 158 \\
\qquad(59.6 \%)\end{array}$ \\
\hline & $\begin{array}{l}\text { Unspecified: } \\
2(0.8 \%)\end{array}$ & $\begin{array}{c}\text { Between } 51 \\
\text { and } 70: 68 \\
(25.7 \%)\end{array}$ & $\begin{array}{l}\text { University/College: } 93 \\
\text { (35.1\%) }\end{array}$ & $\begin{array}{l}\text { Ministry of Health: } 15 \\
(5.7 \%)\end{array}$ & \\
\hline & & $\begin{array}{c}\text { Above } 70: 25 \\
(9.4 \%)\end{array}$ & Unspecified: 2 (0.8\%) & $\begin{array}{l}\text { Other coverage: } 14 \\
(5.3 \%)\end{array}$ & \\
\hline & & $\begin{array}{l}\text { Unspecified: } 3 \\
\quad(1.1 \%)\end{array}$ & & $\begin{array}{l}\text { No medical coverage: } 105 \\
\qquad(39.6 \%)\end{array}$ & \\
\hline
\end{tabular}

Table 1: The participants' demographics. 
The 111 individuals who reported an incidence of red eyes in the last five years reported that the accompanying symptoms were tearing, foreign body sensation, itching, and blurry vision (Figure 1). These symptoms were reported as unilateral in 40 individuals out of 111 (36\%), and bilateral in 54 (48.6\%), while the rest did not specify. Of these 111 individuals, 80 (72.1\%) reported the use of drops, and 93 (83.8\%) consulted someone for this redness and/or drop use. Twenty one out of these 93 initially consulted a pharmacist (22.5\%), and 52 consulted an ophthalmologist (55.9\%) (Figure $2)$. Those who were aware of their diagnosis (84\%) reported having viral conjunctivitis as the most common etiology (23\%) (Table 2).

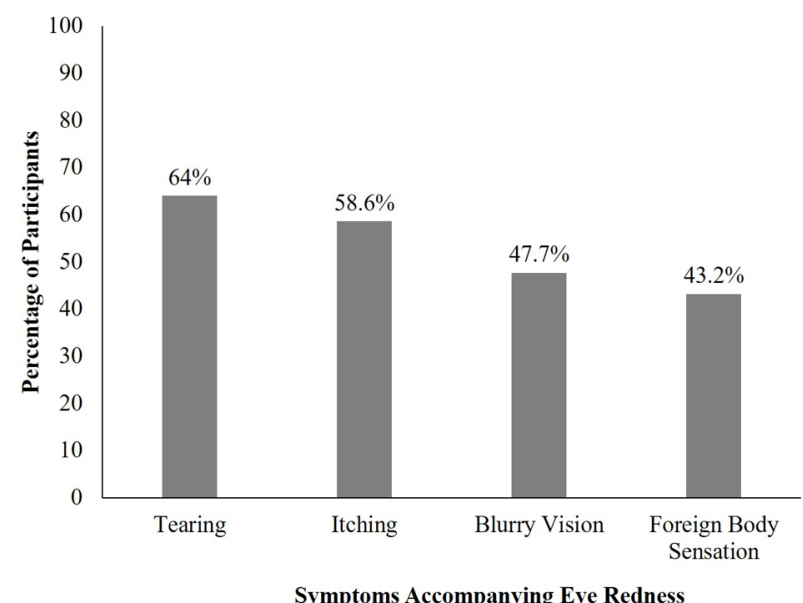

Figure 1: Histogram showing the percentage of participants who reported symptoms accompanying eye redness (tearing, itching, foreign body sensation, and blurry vision).

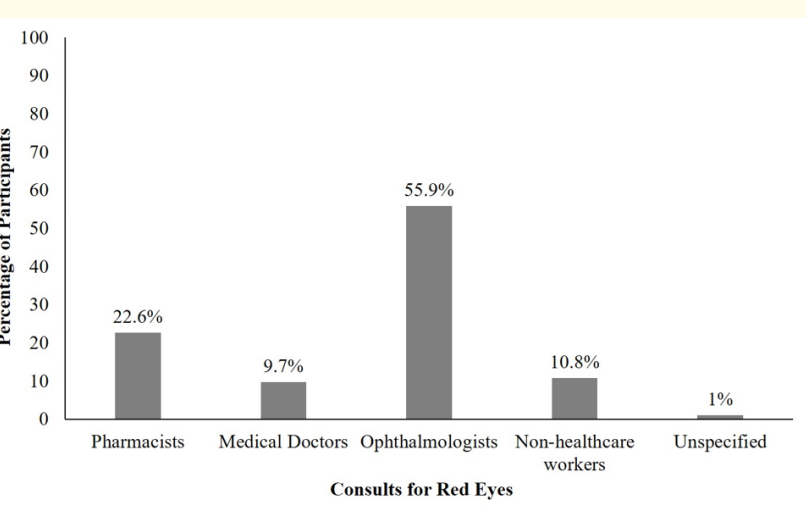

Figure 2: Histogram showing the percentage of participants who consulted pharmacists, medical doctors (includes general practitioners, family doctors, and emergency physicians), ophthalmologists, and non-healthcare workers.

We found a statistically significant correlation between individuals whose ages are between 31 and 50 years and the act of consulting someone $(p=0.019)$. Age also had a statistically significant correlation with whom the participants consulted. Ophthalmologists and pharmacists were more likely to be consulted by individuals between 31 and 50, as opposed to non-healthcare-worker consultations who were more likely sought by individuals aged between 51 and 70 years (Linear-by-linear association $p=0.038$ ). However, age group had no significant correlation with the use of drops in general $(p=0.099)$. Females were more likely than males to ask someone about eye redness, whereby 56 out of 93 (60.2\%) individuals who consulted someone for eye redness were females

\begin{tabular}{|c|c|c|c|c|c|}
\hline Symptom & Allergy & $\begin{array}{c}\text { Viral } \\
\text { Conjunctivitis }\end{array}$ & $\begin{array}{c}\text { Bacterial } \\
\text { Conjunctivitis }\end{array}$ & $\begin{array}{c}\text { Other (Glaucoma, retinal } \\
\text { disease, dry eyes, ...) }\end{array}$ & Unspecified \\
\hline $\begin{array}{l}\text { Percentage of } \\
\text { patients (\%) }\end{array}$ & $18 \%$ & $23 \%$ & $2 \%$ & $41 \%$ & $16 \%$ \\
\hline
\end{tabular}

Table 2: The distribution of diagnoses received by patients.

$(\mathrm{p}=0.01)$

Interestingly, we found no statistically significant correlation between the level of education and the act of consultation for eye redness ( $p=0.716)$ on one hand, and between the level of education and the use of drops on the other hand ( $p=0.558)$. Common health-care coverage types (Insurance, NSS, and Ministry of Health) were not found to be statistically significantly correlated 
with seeing an ophthalmologist; 44 of 51 individuals who sought the opinion of ophthalmologists $(86.3 \%)$ were not insured $(\mathrm{p}=$ $0.605)$. In addition, the area of residence was not found to be statistically significantly correlated with who was consulted $(\mathrm{p}=0.593)$ or with the use of drops ( $p=0.461)$.

All symptoms except itching were significantly correlated with seeking advice from someone in general (healthcare or non-health care worker) (Table 3). Having unilateral symptoms was also sig- nificantly correlated with consulting someone for eye redness $(\mathrm{p}$ $=0.01$ ). Foreign body sensation was the only symptom to be significantly correlated with who was specifically consulted (pharmacist, general practitioner, ophthalmologist...); the majority of individuals with foreign body sensation consulted an ophthalmologist $(44.7 \%)$ and less commonly a pharmacist $(34 \%)(p=0.018)$. Table 3 also shows that only tearing and foreign body sensation were significantly correlated with the use of drops $(p=0.003$ and $p=0.002$ respectively) (Table 3).

\begin{tabular}{|l|c|c|c|c|}
\hline & Itching & Foreign Body Sensation & Tearing & Blurry Vision \\
\hline \multirow{3}{*}{$\begin{array}{l}\text { Consultation in General } \\
\text { for Redness }\end{array}$} & 56 out of 65 & 47 out of 48 & 65 out of 71 & 49 out of 53 \\
& $86.2 \%$ & $97.9 \%$ & $91.5 \%$ & $92.5 \%$ \\
& $(\mathrm{P}=0.391)$ & $(\mathrm{P}>0.001)$ & $(\mathrm{P}=0.002)$ & $(\mathrm{P}=0.016)$ \\
\hline & 48 out of 65 & 42 out of 48 & 58 out of 71 & 42 out of 53 \\
Use of Drops & $73.8 \%$ & $87.5 \%$ & $81.7 \%$ & $79.2 \%$ \\
& $(\mathrm{P}=0.482)$ & $(\mathrm{P}=0.002)$ & $(\mathrm{P}=0.003)$ & $(\mathrm{P}=0.124)$ \\
\hline
\end{tabular}

Table 3: P values of the correlations between eye symptoms and the behavior pattern of participants.

Blurry vision was the only symptom to have a significant correlation with the act of consulting an ophthalmologist after failure of resolution with OTC drops (one-sided exact significance: $\mathrm{p}=$ 0.055). Out of the total number of participants who reported blurry vision (42), 31 individuals (73.8\%) consulted an ophthalmologist later on. Other symptoms had no significant correlation with ophthalmology consultation after OTC drop use failure.

Regarding drop users (82 participants), only 28 individuals (34.1\%) read the eye drop instructions in the pamphlet, and only 13 out of the 82 (15.9\%) were informed/knew about its side effects. Foreign body sensation had a significant correlation with who issued the eye drop prescription/recommended it (pharmacist, relative, friend, medical doctor, or ophthalmologist). Out of 42 persons with this sensation, 26 (61.9\%) had their eye drop prescription/recommendation from an ophthalmologist ( $p=0.057)$. In addition, foreign body sensation in the eye(s) was correlated significantly with the duration of drop use $(p=0.025)$.

We also noted that reading instructions is significantly correlated with level of education, where the majority of those who read instructions had a college level of education (53.6\%), while the majority of those who did not had only reached the elementary school level $(52.8 \%)(p=0.043)$. There was also a borderline significant correlation between area of residence and reading the eye drop instructions. Most individuals residing outside Beirut (72.2\%) did not read them (exact 1 -sided $\mathrm{p}=0.059$ ).

Otherwise, age, gender, level of education, type of financial medical coverage, and area of residence were not found to have a statistically significant correlation with the duration of drop use, being informed about side effects, or consulting an ophthalmologist following drop use.

Having unilateral versus bilateral symptoms did not significantly correlate with duration of drop use, being informed about side effects, reading instructions, or consulting an ophthalmologist following drop use.

When asked about general/flu-like symptoms, 27/265 individuals $(10.19 \%)$ reported they would consult their neighbor for symptoms of fever, cough, or other symptoms in general. Sixty eight percent of individuals $(181 / 265)$ reported they would consult a pharmacist for the same general symptoms.

\section{Discussion}

Since the 1990's there has been a worldwide increase in recognition of self-medication practices [13] and Lebanon is no ex- 
ception. The use of OTC eye drops has always been a widespread practice in Lebanon across all its governorates. Similar research has shown prevalence of this behavior in other countries. In India, a study by Gupta., et al. [10] revealed that $18.2 \%$ of rural inhabitants reported self-medication for ocular symptoms. Similarly, 53\% of the people of Barranquilla, Colombia reported a non-health care worker source for eye medication recommendations [9]. Studies conducted in South America have shown a high rate of self-medication. They also revealed that a significant number of the selfmedicating participants did not read the pamphlet available with the drug and were unaware of the side effects of the medications. They also showed that the first providers of OTC medications were pharmacists $[8,9]$.

Our results show that $43.5 \%$ of individuals with no red eye symptoms in the last five years would consider consulting a pharmacist, and $23.4 \%$ would consider consulting a neighbor/relative/ friend. Of patients with red eye symptoms that consulted someone for redness, $22.5 \%$ consulted pharmacists and 10.8\% consulted non-health care workers. In other words, a marked proportion of the Lebanese population would start using over the counter eye drops without previously getting a medical doctor's or an ophthalmologist's prescription or consult. This is probably due to Lebanese cultural preferences, where the opinions of neighbors, relatives, and friends are valued. Patients also give importance to the pharmacist's choice of medication and medical advice due to ease of obtaining the recommendation and medication concurrently from the same location.

Furthermore, Lebanon lacks guidelines that prohibit dispensing certain medications without a prescription from a physician, except for narcotics. In 2017, the Ministry of Public Health in Lebanon started working on a policy that prevents giving antibiotics without a prescription, but it has not yet been adopted. Medication safety is a significant public health concern, especially in a country like Lebanon where widespread awareness about medication side effects is still lacking [12]. Other developing nations show a similar trend. In India, a study done by Kadri., et al. [11] showed that $89.9 \%$ of pharmacists practice over the counter eye medication dispensing. A study by Marquez., et al. [9] in Latin America showed that $31 \%$ of people living in Córdoba, Argentina reported consulting a pharmacist for ocular symptoms. Also, the sale of eye drops without a prescription has been observed in $77.0 \%$ to $86.0 \%$ of the drugstores in Brazil [14].
We also found that individuals aged 31 to 50 were more likely to consult someone for redness in general, and to consult a pharmacist or an ophthalmologist in specific. This is a working age group that may be motivated to not lose working days due to illness. In contrast, individuals aged 51 to 70 were more likely to consult non-health care workers. This is most likely driven by them acting at their convenience and without a great sense of urgency regarding resolution time. We found similar results with general flu-like symptoms, whereby $68.3 \%$ would consider a pharmacist consult and $10.19 \%$ would consider a non-health care worker consult. Thus, this behavior translates across common non severe medical problems.

The symptoms of foreign body sensation, tearing, and blurry vision (but not itching) increased the likelihood of consulting someone for eye redness, an expected finding. Itching is probably seen as a transient symptom that is self-resolving in a short time without any intervention. Foreign body sensation was the only symptom to be correlated with ophthalmologist or pharmacist consult and blurry vision was the only symptom that increased the chances of consulting an ophthalmologist after OTC eye drop use. This is due to the perception that these symptoms can lead to serious complications if left untreated.

An alarming finding was that only $34.1 \%$ of drop users read instructions, more likely if they resided in Beirut, and only $15.9 \%$ knew about side effects. This consequently endangers the patients' health, and is the major issue related to OTC use of drops. Our findings also suggest that college level of education increases the chances of reading the eye drop instructions/pamphlet, as this education level is often accompanied by better awareness towards health and medication use.

To the best of our knowledge, this is the first study that looks at the pattern of OTC use of drops in Lebanon and the Middle East. One limitation may be the small sample size and this is affected by the number of patients visiting the Ophthalmology Outpatient Department at our institution and agreeing to participate in the study. We also limited our study to adults aged 18 and above and to modern ophthalmic medicine, excluding traditional medicine use and "homemade products" as self-medication.

\section{Conclusion}

As we expected, a large proportion of patients will self-medicate with OTC drops without consulting a medical doctor or reading the

Citation: Joanna S Saade., et al. "A Survey on Self-Medication in Ophthalmology in the Lebanese Population". Acta Scientific Ophthalmology 4.5 (2021): 95-100. 
medication pamphlets. Although fast and convenient, this can be detrimental to the patients' eyes with very few patients aware of the side effects of the drops they use, how to properly use them and what are the adequate frequency and dosage. This might be harmless when considering hydrating eye drops but is more serious when it comes to antibiotic and steroid drops. The latter are sold as OTC drugs in Lebanon while they require prescription in other countries. We attribute this practice to cultural reasons as well as a misplaced reliance on pharmacists' input. Reinforcing this behavior is a lack of government oversight on dispensing drugs. This issue needs to be addressed to provide better care for the Lebanese population, along with developing policies and laws that improve access to adequate healthcare and limit inappropriate consumption of medication.

\section{Conflict of Interest}

No conflicts of interest nor financial interest exist. The study was not sponsored.

\section{Bibliography}

1. Ruiz Maria Esperanza. "Risks of self-medication practices". Current Drug Safety 5.4 (2010): 315-323.

2. Fraunfelder FT and Meyer SM. "Ocular toxicology update". Australian and New Zealand Journal of Ophthalmology 12.4 (1984): 391-394.

3. Butcher JM., et al. "Bilateral cataracts and glaucoma induced by long term use of steroid eye drops". British Medical Journal 309.6946 (1994): 43.

4. Raizman M. "Corticosteroid therapy of eye disease. Fifty years later". Archives of Ophthalmology 114.8 (1996): 1000-1001.

5. Kim Stephen J., et al. "Nonsteroidal anti-inflammatory drugs in ophthalmology". Survey of Ophthalmology 55.2 (2010): 108133.

6. Wilson FM. "Adverse external ocular effects of topical ophthalmic medications". Survey of Ophthalmology 24.2 (1979): 57-88.

7. Gaynor BD., et al. "Topical ocular antibiotics induce bacterial resistance at extraocular sites". The British Journal of Ophthalmology 89.9 (2005): 1097-1099.
8. Marquez Gabriel E., et al. "Self-medication in ophthalmology: a questionnaire-based study in an Argentinean population". Ophthalmic Epidemiology 19.4 (2012): 236-241.

9. E Marquez Gabriel. "Eye Drop Self-Medication: Comparative Questionnaire-Based Study of Two Latin American Cities". Journal of Clinical and Experimental Ophthalmology 05.02 (2014).

10. Gupta Noopur., et al. "Use of traditional eye medicine and selfmedication in rural India: A population-based study”. PloS one 12.8 (2017): e0183461.

11. Kadri Rajani., et al. "Over the counter ophthalmic drug misuse, are we aware?" The Online Journal of Health and Allied Sciences 9.2 (2010): 11.

12. Bennadi Darshana. "Self-medication: A current challenge". Journal of Basic and Clinical Pharmacy 5.1 (2013): 19-23.

13. Ramia Elsy., et al. "Assessment of patients' knowledge and practices regarding their medication use and risks in Lebanon". International Journal of Clinical Pharmacy 39.5 (2017): 10841094.

14. Lira Pedro Cavalcanti., et al. "Venda De Colírios, Sem Receita Médica, Em Farmácias Com Serviço De Entrega a Domicílio". Arquivos Brasileiros De Oftalmologia 62.3 (1999).

\section{Assets from publication with us}

- Prompt Acknowledgement after receiving the article

- Thorough Double blinded peer review

- Rapid Publication

- Issue of Publication Certificate

- High visibility of your Published work

Website: www.actascientific.com/

Submit Article: www.actascientific.com/submission.php

Email us: editor@actascientific.com

Contact us: +919182824667 